\title{
Determination of the red bed soft rock’s apparent preconsolidation pressure
}

\author{
Longlong $\mathrm{Lv}^{\text {i) }}$, Hongjian Liao ${ }^{\text {ii)}}$, Li Song ${ }^{\text {iii)}}$, Yingpeng $\mathrm{Fu}^{\text {i) }}$ and Musanyufu J. Natukunda ${ }^{\text {iv) }}$ \\ i) Ph.D Student, School of Human Settlements and Civil Engineering, Xi'an Jiaotong University, Xi'an, 710049, China. \\ ii) Professor, School of Human Settlements and Civil Engineering, Xi'an Jiaotong University, Xi'an, 710049, China. \\ iii) Corresponding Author, Associate Professor, School of Human Settlements and Civil Engineering, Xi'an Jiaotong University, Xi’an, \\ 710049, China. \\ iv) Master Student, School of Human Settlements and Civil Engineering, Xi’an Jiaotong University, Xi’an, 710049, China.
}

\begin{abstract}
Apparent preconsolidation pressure is an important parameter for soft rock. In this paper, investigated red bed soft rock was taken from Dingxi region, Gansu province, China. In order to obtain the apparent preconsolidation pressure of the soft rock, firstly, a new YS-1 high pressure oedometer was redesigned and used in the step loading confined compression experiments. Due to the soft rock's low compressibility, the compressive curve was flat. Numerical mapping method was proposed considering curvature variation of the curve was not obvious. Secondly, the actual boundary condition which is the void ratio should monotonically decrease with the vertical pressure in the given domain was introduced. The existing 7 mathematical models were compared using the new defined conditions. The results showed that the Harris model was in good agreement with the compressive experimental results. Finally, the apparent preconsolidation pressure of the soft rock was calculated using the equations established in this research.
\end{abstract}

Keywords: apparent preconsolidation pressure, red bed soft rock, numerical mapping method, Harris model

\section{INTRODUCTION}

Preconsolidation pressure is a soil mechanics concept which is an important index to estimate the soil stress history and a significant parameter in the calculation of soil deformation and settlement. Essentially preconsolidation pressure is the compressive yield stress of soil initial structure by mechanical compaction (Hong and Tsuchida 1999). Soft rocks also have a similar characteristic stress. Nygard et al. (2004 and 2006) carried out confined compression tests which were used to obtain soil preconsolidation pressure on KWC Shale and KBC Shale, and got a characteristic stress named apparent preconsolidation pressure. Subsequently, Gutierrez et al. (2008), Liu et al. (2015), Yuan et al. (2017) carried out the same tests on different kinds of soft rock to obtain the apparent preconsolidation pressure, and these test results all indicate that the characteristic pressure equals to the soft rock brittle-ductile transition pressure. So it is essential to take full consideration of the apparent preconsolidation pressure in practical engineering design for getting more rational and practical results of such soft rock.

Red bed soft rock consists of Cenozoic and Mesozoic sediments and usually appears red, deep red or brown due to the ingredient $\mathrm{Fe}^{3+}$. The soft rock is extremely sensitive to water and easily get expensed and disintegrated whenever encountering water due to the rich clay minerals and poor diagenesis. The red bed soft rock society was separated from the soft rock branch officially in China Rock 2018 academic conference, and the first academic conference was held specially for red bed soft rock. Obviously, this type of rock owns significant research value and engineering particularity. Considering the water sensitivity of the soft rock, the deterioration of mechanical properties and failure mechanism under water-rock coupling effect was studied by Liu et al. (2018) and Yan et al. (2018). However, limited field study of the red bed soft rock's apparent preconsolidation pressure has been reported.

During the soil sampling and preparation process, stress relief and structural disturbances inevitably occur, which lead to the deviation of the initial or full segment of the experimental compression curve with the true curve. Therefore, it is necessary to calibrate the preconsolidation pressure obtained in the laboratory test. Casagrande method is the most recognized and widely used technique in the world (Casagrande 1936). However, the $e$-log $\mathrm{P}$ curve of rock and soil with low compressibility is relatively gentle, and the point of the maximum curvature is hardly found, leading to possible unsafe prediction of settlements (Sridharan et al. 1991). Jiang et al. (2003), Wang et al. (2005), Chang et al. (2009), Liu et al. (2009) and Lang et al. (2012) fitted different kinds of soil compression curves using Fourth 
Polynomial, Harris, Cubic Smoothing Spline and Cubic Polynomial, first Gaussian model, respectively, then used Casagrande numerical mapping method to obtain the preconsolidation pressure. Current researches only used fitting R-square value and difference from test value to confirm the fitting model, but the veracity and stability of the model cannot be verified due to lack of evaluation conditions.

The research is organized as follows in this paper. Firstly, step loading confined compression experiments were conducted on the revised YS-1 high pressure oedometer and two groups of valid experimental data of red-bed soft rock in Dingxi were obtained. Secondly, 7 existing mathematical models were used to fit the experimental data and the one applicable for the red-bed soft rock is found according to the model evaluation conditions. Finally, the apparent preconsolidation pressure is obtained by the numerical mapping method of Casagrande. This work lays the foundation for subsequent engineering construction on rock and soil with low compressibility.

\section{EXPERIMENT}

\subsection{Sample preparation}

Rock samples in this research are taken from the LYS-1 section of Lanyu railway Humaling tunnel in Dingxi, Gansu Province, with the embedded depth about $218-220 \mathrm{~m}$, and the geographical coordinates are $104^{\circ} 16^{\prime} \mathrm{E}, 35^{\circ} 31^{\prime} \mathrm{N}$. The maximum effective vertical stress is calculated as Eq.1 (Bishop and Blight 1963):

$$
\sigma_{\text {z } \max }^{\prime}=\left(\sigma_{\text {zmax }}-u_{a}\right)+\chi\left(u_{a}-u_{w}\right)
$$

where $\sigma_{z \max }$ is the maximum vertical stress that the sediment has been subjected, $u_{\mathrm{a}}$ is the pore air pressure, $u_{\mathrm{w}}$ is the hydrostatic pressure, and $\chi$ is the effective stress parameter. According to the geological exploration data, the $\sigma_{z \max }^{\prime}$ at the sampling depth is about 3090-3120 kPa. And the physical and mechanical indices of the soft rock are listed in Table 1.

Table 1. Properties of experimental material.

\begin{tabular}{lcl}
\hline Parameter & Unit & Range \\
\hline Initial void ratio $e_{0}$ & - & $0.196-0.217$ \\
Grain unit weight $\gamma_{S}$ & $\mathrm{kN} / \mathrm{m}^{3}$ & $26.39-26.43$ \\
Natural Water content $w$ & $\%$ & $7.61-8.10$ \\
Disintegrate resistance coefficient $I_{d}$ & $\%$ & $71.59-74.81$ \\
Unconfined compressive strength $\sigma_{C}$ & $\mathrm{MPa}$ & $10.20-14.16$ \\
Young's modulus $E$ & $\mathrm{GPa}$ & $1.11-1.21$ \\
Poisson's ratio $\mu$ & - & $0.35-0.44$ \\
\hline
\end{tabular}

A $32 \mathrm{~mm}$ diameter drill was used in the sample processing. A radial drilling machine was first used to drill the rock mass, then the lathe was used for precision machining. The rock mass was processed into smooth cylinder samples with $30.4 \mathrm{~mm}$ diameter and $45( \pm 3) \mathrm{mm}$ height, and then the two end surfaces were burnished with 200 mesh fine sand paper to the height of $40 \mathrm{~mm}$. The allowable unevenness of the two end surfaces is $0.2 \mathrm{~mm}$.

\subsection{Experiment system}

The apparent preconsolidation pressure is also the compressive yield stress of soft rock's initial structure. Therefore, the method to obtain the soft rock's characteristic stress is similar to the method of obtaining the soil preconsolidation pressure. The step loading confined compression experiment should be conducted. YS-1 high pressure oedometer was applied in this experimental investigation. The compression container of the YS-1 high pressure consolidation oedomter is a round copper container. The sample is cut with a stainless steel ring knife and installed in the inner ring of the container. The porous stone and filter paper are placed on both top and bottom sides of the sample. The samples have two kinds of area size, 30 $\mathrm{cm}^{2}$ and $50 \mathrm{~cm}^{2}$.

The ring knife is usually used to cut the samples in the consolidation experiment, but it is not applicable in cutting hard undisturbed soils and soft rocks. The maximum pressure that the oedometer can afford at present is only $4000 \mathrm{kPa}$. As the maximum curvature point cannot be measured in the curve of red bed soft rock from Dingxi, it is necessary to increase the upper limit pressure and solve the problem of the ring knife not being able to cut such kind of samples.

The original consolidation container of the YS-1 oedomter is replaced in this research. Due to the study that scale effects are insignificant at high confining stresses (Gutierrez et al. 1996), the maximum stress that the oedometer afforded can be increased only by reducing the sample area. The inner diameter of the revised container's guard ring is $30.4 \mathrm{~mm}$. Therefore, the upper limit pressure of the redesigned high-pressure container is 16.5 MPa (shown in Figure 1).

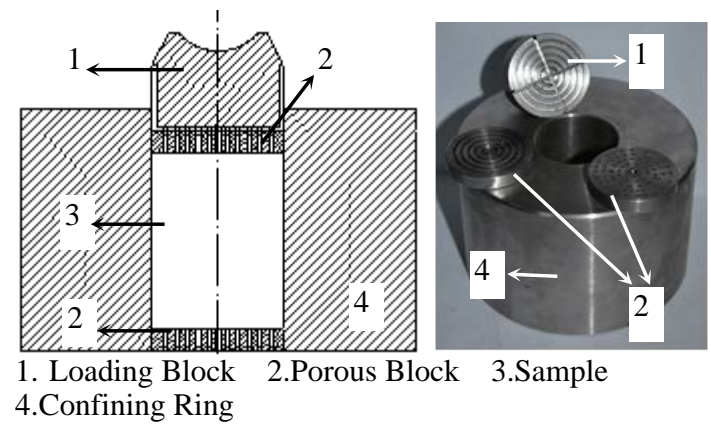

Fig. 1. Redesigned consolidation container.

The new container material is \#45 steel with Young's modulus of $220 \mathrm{GPa}$. Despite the fact that the sample fits perfectly in the oedometer cell, the soft rock 
is composed of particles that create tiny gaps in the local part. Therefore, the sample undergoes elastic compaction phase and confinement compression phase in the loading process. In the first stage:

$$
\begin{aligned}
& \varepsilon_{x}=\frac{1}{E}\left[\sigma_{x}^{\prime}-\mu\left(\sigma_{y}^{\prime}+\sigma_{z}^{\prime}\right)\right] \\
& \varepsilon_{y}=\frac{1}{E}\left[\sigma_{y}^{\prime}-\mu\left(\sigma_{x}^{\prime}+\sigma_{z}^{\prime}\right)\right] \\
& \varepsilon_{z}=\frac{1}{E}\left[\sigma_{z}^{\prime}-\mu\left(\sigma_{x}^{\prime}+\sigma_{y}^{\prime}\right)\right]
\end{aligned}
$$

where $E$ is Young's modulus and $\mu$ is Poisson's ratio. At the beginning of the test $\sigma_{\mathrm{x}}^{\prime}=\sigma_{\mathrm{y}}^{\prime}=0$, the vertical effective stress produces a horizontal strain, which makes the tiny gaps disappear. This phase is very short, then the sample enters second stage confined compression.

\subsection{Experiment scheme and results}

Step loading confined compression experiments on the redesigned oedometer were conducted. In order to reduce influence of friction between sample and oedometer on test results, Vaseline should be applied to samples and the ring inner wall, before the sample is placed in the confining ring. According to the standard of the geotechnical test method GB/T50123-1999 (2001), the load rate is 0.5 , and the height variation of the sample was measured in $24 \mathrm{~h}$ for each loading step. Two groups of the valid consolidation experiment data are listed in Table 2. Sample BG-01 and BG-02 were taken from the embedded depth $220 \mathrm{~m}$ and $218 \mathrm{~m}$, respectively.

Table 2. Test results of red-bed soft rock preconsolidation pressure.

\begin{tabular}{llll}
\hline $\begin{array}{l}\text { Pressure } \\
(\mathrm{kPa})\end{array}$ & $\begin{array}{l}\text { BG-01 } \\
\text { Void Ratio }\end{array}$ & $\begin{array}{l}\text { BG-02 } \\
\text { Void Ratio }\end{array}$ & $\log P$ \\
\hline 1 & 0.20297 & 0.20347 & 0 \\
206.66 & 0.20171 & 0.20092 & 2.315254 \\
413.32 & 0.20060 & 0.19838 & 2.616284 \\
826.64 & 0.19949 & 0.19666 & 2.917314 \\
1653.27 & 0.19830 & 0.19408 & 3.218344 \\
2479.91 & 0.19648 & 0.19222 & 3.394435 \\
3719.86 & 0.19486 & 0.19033 & 3.570527 \\
5373.13 & 0.19315 & 0.18721 & 3.730228 \\
7853.04 & 0.19096 & 0.18406 & 3.895038 \\
11572.90 & 0.18783 & 0.17859 & 4.063442 \\
16532.72 & 0.18445 & 0.17344 & 4.218344 \\
\hline
\end{tabular}

\section{NUMERICAL MAPPING METHOD}

The techniques for calibrating $P_{\mathrm{C}}$ on compression curve include $e$ vs. log P method (Casagrande 1936), $\ln (1+e)$ vs. $\log P$ method (Butterfield 1979), $\lg (1+e)$ vs. log P method (Sridharan et al. 1991), compression index method (Boone and Storer 2010), and so on. The most widely accepted and used one still is the Casagrande method. The detailed steps for Casagrande method are demonstrated in Figure 2. Line $l_{P}$ is the angle bisector line of the horizontal and tangent lines of the maximum curvature point. Line $l_{C}$ is the extension line of the straight segment of the curve, and the slope of the line $l_{C}$ is the compression index expressed by C.

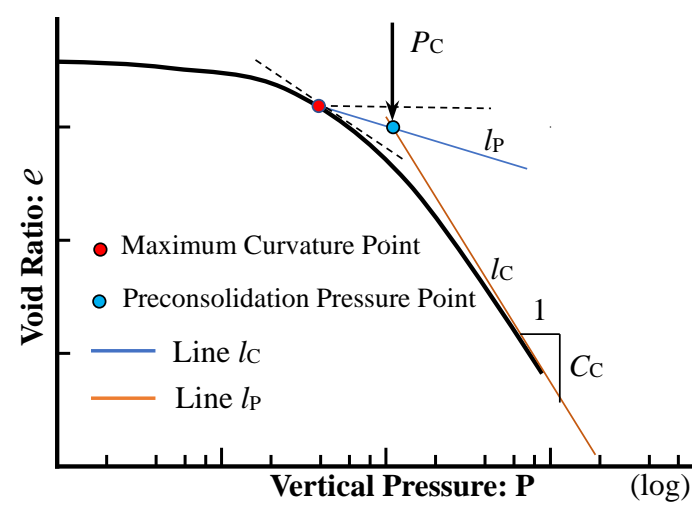

Fig. 2. Sketch of Casagrande method.

The Casagrande method is applicable for soils with distinct curvature change of $e$-log $\mathrm{P}$ curve. For compression curves of the soil and soft rock with low compressibility, it is difficult to obtain the point of the maximum curvature hence the numerical mapping method is proposed. The essence of the numerical mapping method is using the regression curve of the mathematical model to solve the maximum curvature and to determine the location by solving the simultaneous equations instead of manual mapping.

The mathematical model of the numerical mapping method needs to satisfy three boundary conditions (Lang et al. 2012): (1) the void ratio of the soil is a non-zero value before loading; (2) the curve tends to be straight when $\mathrm{P}$ reaches a stable value; (3) the void ratio approaches zero when consolidation pressure gradually increases to a larger value.

When the vertical stress is $1 \mathrm{kPa}$, the void ratio can be approximated to the initial void ratio, $e_{0}$. In order to satisfy the boundary condition (1), test point $\left(1, e_{0}\right)$ is added in the experimental data. Many experimental studies (Chang et al. 2009, Boone and Storer 2010) have shown that the final part of the compression curve is close to a straight line. The curve is divided into two parts, the curved part and the straight part, to satisfy the boundary condition (2) and (3). So treat the first eight points as the curved part, and the last three points as the straight part.

\subsection{Experimental data fitting of the curved part}

There are mainly 7 mathematical models to fit the preconsolidation curve from the current studies. As follows: 
3rd Polynomial: $\quad e=\sum_{\mathrm{i}=1}^{3} a_{\mathrm{i}} \cdot(\log P)^{\mathrm{i}}+a_{4}$

4th Polynomial: $e=\sum_{\mathrm{i}=1}^{4} a_{\mathrm{i}} \cdot(\log P)^{\mathrm{i}}+a_{5}$

$$
\text { Harris: } e=\frac{1}{a_{1}+a_{2} \cdot(\log P)^{a_{3}}}
$$

$$
\begin{aligned}
& \text { Logistic: } e=a_{1}+a_{2} \cdot\left(1+\mathrm{e}^{a_{3}\left(\log P-a_{4}\right)}\right)^{-1} \\
& \text { Gompertz: } e=a_{1}+a_{2} \cdot \mathrm{e}^{-a_{3}\left(\log P-a_{4}\right)}
\end{aligned}
$$

$$
\text { 1st Gaussian: } e=a_{1} \cdot \mathrm{e}^{-\left(\frac{\log P-a_{2}}{a_{3}}\right)^{2}}
$$

$$
\text { 2nd Gaussian: } e=a_{1} \cdot \mathrm{e}^{-\left(\frac{\log P-a_{2}}{a_{3}}\right)^{2}}+a_{4} \cdot \mathrm{e}^{-\left(\frac{\log P-a_{5}}{a_{6}}\right)^{2}}
$$

where $a_{\mathrm{i}}$ in the above formula are the coefficients of the fitting model, $e$ is the void ratio, and $P$ is the vertical stress. The experimental data in this paper were fitted using the above seven mathematical models respectively, fitting coefficients and R-square value of the corresponding mathematical model for BG-01 and BG-02 experimental data are listed in Table 3.

$\mathrm{R}$-square value can directly reflect the fitting degree of the mathematical model on the experimental data, the nearer to 1 the $\mathrm{R}$-square is, the closer the mathematical model fitting is to practical condition. The fitting results of Logistic model and Gomportz model did not match the experimental data, and thus these two models were excluded. From the fitting results, the more fitting coefficient numbers, the higher the fitting accuracy. The R-square value of two samples' Quartic Polynomial model are 0.9993 and 0.9995, Second Gaussian model are 0.9991 and 0.9995, which are the closest two models compared with 1 among the other five fitting equations. It is shown that the Quartic Polynomial model and Second Gaussian model have the better agreement with the experimental data. However, the veracity and stability of the fitting model can't be verified. A new boundary condition should be presented to evaluate the model's applicability. The void ratio should monotonically decrease with the vertical pressure in the given domain that is named as actual boundary condition. The new condition can be expressed as follow:

$$
\frac{\partial e}{\partial \log P}<0, \quad \log P \in\left(0, \log P_{\max }\right)
$$

where $P_{\max }$ is the maximum vertical pressure in the fitting curved part. Only the Harris model satisfies the actual boundary condition, by taking the partial derivatives of the five fitting models. In addition, there are only three fitting coefficients in the model, the
Harris model's R-square values are also 0.9956 and 0.9738 for sample BG-01 and BG-02, respectively.

Above all, it is rational to choose the Harris model as the mathematical model to fit the curve part of $e$-log $\mathrm{P}$ for the Dingxi red bed soft rock. Harris model were plotted and shown in Figure 3.

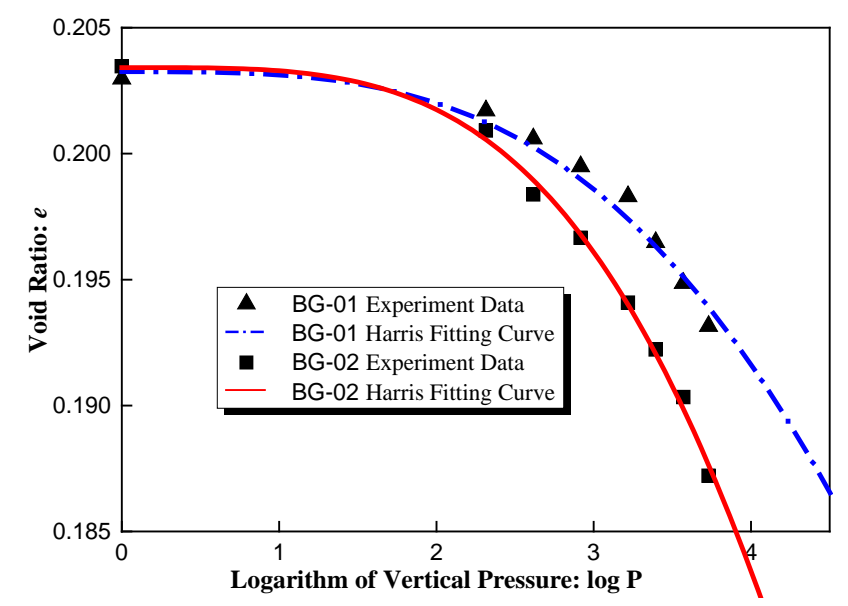

Fig. 3. Harris fitting curves of samples.

\subsection{Experimental data fitting of the straight part}

The experimental data of the last 3 steps loading of the samples were fitted with linear equation of $l_{C}$ as follows:

$$
e=-C_{\mathrm{C}} \cdot \log P+z
$$

where $z$ is the fitting coefficient. The fitting results are shown in Table 4 and the R-square value indicates that the fitting results are in good agreement with the experimental results.

\subsection{Determination of the apparent preconsolidation pressure}

To obtain apparent preconsolidation pressure, the maximum curvature point should be obtained first, according to Casagrande method. Curve curvature is calculated as follows:

$$
\Gamma=\frac{\left|e^{\prime \prime}\right|}{\left(1+e^{\prime 2}\right)^{\frac{3}{2}}}
$$

where $e^{\prime}$ is the void ratio's partial derivative with respect to $\log \mathrm{P}$, and $e^{\prime \prime}$ is the void ratio's second partial derivative with respect to $\log P$. Because the soft rock's e-log P curve fitting model is Harris model, $e^{\prime}$ and $e^{\prime \prime}$ can be expressed as follow:

$$
\begin{gathered}
e^{\prime}=\frac{a_{2} a_{3}(\log P)^{a_{3}}}{\log P \cdot\left[a_{1}+a_{2} \cdot(\log P)^{a_{3}}\right]^{2}} \\
e^{\prime \prime}=\frac{a_{2} a_{3}(\log P)^{a_{3}-2} \cdot\left[a_{1}-a_{1} a_{3}+a_{2}(\log P)^{a_{3}}+a_{2} a_{3}(\log P)^{a_{3}}\right]}{\left[a_{1}+a_{2} \cdot(\log P)^{a_{3}}\right]^{3}}
\end{gathered}
$$


Substitute Eq.13 and Eq.14 into Eq.12, e-log P curve curvature $\Gamma_{\text {Harris }}$ is obtained as:

Table 3. The BG-01 and BG-02 fitting results of 7 fitting models.

\begin{tabular}{|c|c|c|c|c|c|c|c|}
\hline Fitting Model & $\begin{array}{l}\text { 3rd } \\
\text { Polynomial }\end{array}$ & $\begin{array}{l}\text { 4th } \\
\text { Polynomial }\end{array}$ & Harris & Logistic & Gompertz & 1st Gaussian & 2nd Gaussian \\
\hline$a_{1}$ & $\begin{array}{l}-\mathbf{0 . 0 0 1 5 3} \\
-0.00101\end{array}$ & $\begin{array}{l}-\mathbf{0 . 0 0 1 3 1} \\
-0.00045\end{array}$ & $\begin{array}{l}4.916 \\
4.920\end{array}$ & $\begin{array}{l}-\mathbf{- 0 . 9 8 9 3} \\
0.1715\end{array}$ & $\begin{array}{l}\mathbf{0 . 1 1 3 7} \\
0.1621\end{array}$ & $\begin{array}{l}\mathbf{0 . 2 0 7 6} \\
0.206\end{array}$ & $\begin{array}{l}\mathbf{0 . 2 0 9 5} \\
0.2054\end{array}$ \\
\hline$a_{2}$ & $\begin{array}{l}\mathbf{0 . 0 0 7 2 1} \\
0.00473\end{array}$ & $\begin{array}{l}\mathbf{0 . 0 1 1 5 8} \\
0.00350\end{array}$ & $\begin{array}{l}\mathbf{0 . 0 0 3 0 9} \\
0.00309 \\
\end{array}$ & $\begin{array}{l}2.547 \\
2.547\end{array}$ & $\begin{array}{l}\mathbf{0 . 0 9 3 1 9} \\
0.04399 \\
\end{array}$ & $\begin{array}{l}\mathbf{1 . 1 4 6} \\
1.217\end{array}$ & $\begin{array}{l}\mathbf{0 . 9 2 0 3} \\
0.9159 \\
\end{array}$ \\
\hline$a_{3}$ & $\begin{array}{r}-\mathbf{0 . 0 1 0 0 5} \\
-0.00625 \\
\end{array}$ & $\begin{array}{r}-\mathbf{0 . 0 3 5 6 5} \\
-0.01001 \\
\end{array}$ & $\begin{array}{l}3.7190 \\
3.297 \\
\end{array}$ & $\begin{array}{l}\mathbf{0 . 0 1 0 1 4} \\
458.7 \\
\end{array}$ & $\begin{array}{l}\mathbf{0 . 0 6 9 5} \\
0.0924 \\
\end{array}$ & $\begin{array}{l}\mathbf{7 . 7 1 0} \\
9.540 \\
\end{array}$ & $\begin{array}{l}\mathbf{5 . 3 8 4} \\
8.946 \\
\end{array}$ \\
\hline$a_{4}$ & $\begin{array}{l}\mathbf{0 . 2 0 3 5} \\
0.2030 \\
\end{array}$ & $\begin{array}{l}\mathbf{0 . 0 3 5 6 3} \\
0.00947 \\
\end{array}$ & 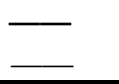 & $\begin{array}{l}\mathbf{1 1 . 4 4} \\
69.38 \\
\end{array}$ & $\begin{array}{l}\mathbf{0 . 3 3 8 7} \\
0.0780 \\
\end{array}$ & 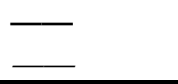 & $\begin{array}{l}\mathbf{0 . 0 2 9 8 2} \\
0.00917 \\
\end{array}$ \\
\hline$a_{5}$ & 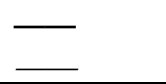 & $\begin{array}{l}\mathbf{0 . 2 0 3 5} \\
0.203\end{array}$ & 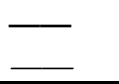 & - & 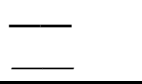 & 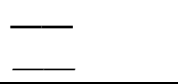 & $\begin{array}{l}4.076 \\
3.790\end{array}$ \\
\hline$a_{6}$ & $\bar{\square}$ & $\bar{\square}$ & $\bar{Z}$ & $\bar{Z}$ & $\bar{Z}$ & $\bar{Z}$ & $\begin{array}{l}1.319 \\
1.164\end{array}$ \\
\hline R-square & $\begin{array}{l}\mathbf{0 . 9 9 4 3} \\
0.9969\end{array}$ & $\begin{array}{l}\mathbf{0 . 9 9 9 5} \\
0.9993\end{array}$ & $\begin{array}{l}\mathbf{0 . 9 9 5 6} \\
0.9738\end{array}$ & $\begin{array}{l}\mathbf{0 . 6 6 1 1} \\
0.5964\end{array}$ & $\begin{array}{l}\mathbf{0 . 6 1 5 3} \\
0.5682\end{array}$ & $\begin{array}{l}\mathbf{0 . 9 5 9 7} \\
0.9641\end{array}$ & $\begin{array}{l}\mathbf{0 . 9 9 9 5} \\
0.9991\end{array}$ \\
\hline
\end{tabular}

Note: The results of sample BG-01 and BG-02 are shown as bold fonts and italics, respectively.

Table 4. The numerical fitting results of the straight part.

\begin{tabular}{cccc}
\hline Sample & $C_{\mathrm{C}}$ & $\mathrm{Z}$ & R-square \\
\hline BG-01 & 0.03284 & 0.312 & 0.9999 \\
BG-02 & 0.02011 & 0.2694 & 0.9998 \\
\hline$\Gamma_{\text {Haris }}=\left|\frac{a_{2} a_{3}(\log P)^{\left(a_{3}-2\right)} \cdot\left[a_{1}-a_{1} a_{3}+a_{2}(\log P)^{a_{3}}+a_{2} a_{3}(\log P)^{a_{3}}\right]}{\left\{\frac{a_{2}{ }^{2} a_{3}^{2}(\log P)^{2 a_{3}-2}}{\left[a_{1}+a_{2}(\log P)^{a_{3}}\right]^{4}+1}\right\} \cdot\left[a_{1}+a_{2}(\log P)^{a_{3}}\right]^{3}}\right|$
\end{tabular}

Compute the stationary point of Eq.15, when $\log P \in\left(0, \log P_{\max }\right)$. The point's abscissa is $\log \mathrm{P}_{\mathrm{m}}$, and ordinate is $e_{\mathrm{m}}$. The equation of the angular bisector line $l_{\mathrm{P}}$ of the maximum point horizontal line and tangent line is obtained as:

$$
\log P-\log P_{m}=\tan \left(\frac{\tan ^{-1} e_{m}{ }^{\prime}}{2}\right) \cdot\left(e-e_{m}\right)
$$

where $e_{\mathrm{m}}^{\prime}$ is the slope of stationary point's tangent line, and it can be obtained by substituting $\log \mathrm{P}_{\mathrm{m}}$ into Eq.13. The intersection abscissa of the line $l_{\mathrm{P}}$ and the straight part line $l_{\mathrm{C}}$ can be obtained by combing Eq.11 and Eq.16, then the value of apparent preconsolidation pressure can be obtained.

By the above-mentioned methods, the apparent preconsolidation pressure of sample BG-01, BG-02 can be calculated as $4680 \mathrm{kPa}$ and $4530 \mathrm{kPa}$, respectively. The pressure is much higher than the pressure deduced from geological evidence. The same conclusion was also shown in current studies (Cotecchia et al. 1997; Nygard et al. 2006; Gutierrez et al. 2008).

\section{DISCUSSION}

Preconsolidation pressure is the compressive yield stress of the soil initial structure. In the process of soil formation, soil forms an original structure with the vertical effective stress increasing. From the concept of soil preconsolidation pressure, the strength of the original structure equals to maximum vertical effective stress. Therefore, the original soil structure is only generated by mechanical compaction. Soft rock also forms an original structure whose compressive yield stress is called apparent preconsolidation pressure by Nygard et al. (2006), in the deposition process. Due to the experience of different degrees of diagenesis which includes metasomatism, crystallization, leaching, hydration and biochemistry, cementation between the soft rock particles formed. The apparent preconsolidation pressure is composed of not only the maximum vertical effective stress that soft rock has subjected, but also the strength of cementation which was formed by diagenesis. So the apparent preconsolidation pressure is higher than the preconsolidation pressure deduced from geological evidence, and the differences between the two pressures depends on the strength of cementation formed by diagenesis.

\section{CONCLUSIONS}

(1) The compression curve fitting process should be divided into two parts to be fitted: the curved part and the straight part.

(2) In order to fit the compression curve more accurately and practically, the monotone decreasing boundary condition in the given domain was introduced together with the three conditions of numerical plotting method.

(3) Due to the model's veracity stability and simplicity, Harris model is more suitable than other 6 models for fitting $e$-log P curve part.

(4) The apparent preconsolidation pressure of red 
bed soft rock samples in Dingxi with embedded depth $218 \mathrm{~m}$ and $220 \mathrm{~m}$ are $4680 \mathrm{kPa}$ and $4530 \mathrm{kPa}$, respectively.

(5) The apparent preconsolidation pressure is higher than the preconsolidation pressure deduced from geological evidence, and the difference depends on the degree of diagenesis.

\section{ACKNOWLEDGEMENTS}

The work was supported by the Natural Science Foundation of China (51879212, 41630639); Science and Technology Co-ordination and Innovation Project of Shaanxi Province in China (Grant No.2016KTZDSF03-02) and CMEC 2017 Science and Technology Research and Development Fund Project (Grant No. CMEC-KJYF-2017-05).

\section{REFERENCES}

1) Bishop, A.W. and Blight, G.E. (1963): Some Aspects of Effective Stress in Saturated and Partly Saturated Soils, Géotechnique, 13 (3), 177-197.

2) Boone and Storer, J. (2010): A Critical Reappraisal of "Preconsolidation Pressure" Interpretations Ssing the Oedometer Test, Canadian Geotechnical Journal, 47, 281-296.

3) Butterfield, R. (1979): A Natural Compression Law for Soils (an advance on e-log p'), Géotechnique, 29, 469-480.

4) Casagrande, A. (1936): The Determination of the Preconsolidation Load and Its Practical Significance, In Proceedings of the 1st International Conference on Soil Mechanics and Foundation Engineering, Cambridge, Mass. Vol. 3, pp. 60-64.

5) Chang, L.Y., Wang, J.C. and Zhu, X.R. (2009): Nonparametric Fitting Model for Determining Soil Preconsolidation Pressure, Rock and Soil Mechanics, 30(5): 1337-1342 (in Chinese).

6) Cotecchia, F., Chandler, R.J. and Anonymous. (1997): The Influence of Structure on the Pre-failure Behaviour of a Natural Clay, Géotechnique, 47(3), 523-544.

7) Gutierrez, M., Berre, T., Høeg, K. and Nagel, N. (1996): Laboratory Testing and Modelling of Scale Effects in Chalk, Proceedings of the Fifth North Sea Chalk Symposium, Reims, France, October 7-9, 1996, Paper no. $\mathrm{X}-4$.

8) Gutierrez, M., Nygard, R., Høeg, K. and Berre, T. (2008): Normalized Undrained Shear Strength of Clay Shales, Engineering Geology, 99(1), 31-39.

9) Hong, Z. and Tsuchida, T. (1999): On Compression Characteristics of Ariake Clays, Canadian Geotechnical Journal, 36(5), 807-814.

10) Jiang, A.L., Zhao, C.F. and Gao, D.Z. (2003): Mathematical Model Method of Determining Preconsolidation Pressure, Rock and Soil Mechanics, 24(2), 292-295 (in Chinese).

11) Lang, L.Z., Xiang, W., Lou, R.R. and Jia, H.L. (2012): Mathematic Models for Determing Preconsolidation Pressure and Application, Journal of Engineering Geology, 20(5), 657-662 (in Chinese).

12) Liu, J.X., Yang, C.H., Liu, W., Huo, L. and Mao, H.P. (2015): Apparent Preconsolidation Stress and Sealing Characteristics of Argillaceous Cap Rocks, Chinese Journal of Rock Mechanics and Engineering, 34(12), 2377-2387 (in Chinese).
13) Liu, Y.H., Zhu, X.R. and Chang, L.Y. (2009): Determining Preconsolidation Pressure by Mathematic Analysis Based on Casagrande Method, Rock and Soil Mechanics, 30(1), 211-214 (in Chinese).

14) Liu, Z., Zhou, C.Y., Li, B.T., Lu, Y.Q. and Yang, X. (2018): A Dissolution-diffusion Sliding Model for Soft Rock Grains with Hydro-mechanical Effect, Journal of Rock Mechanics and Geotechnical Engineering, 10(3), 457-467 (in Chinese).

15) Nygard, R., Gutierrez, M., Gautam, R. and Høeg, K. (2004): Compaction Behavior of Argillaceous Sediments as Function of Diagenesis, Marine and Petroleum Geology, 21(3), 349-362.

16) Nygard, R., Gutierrez, M., Bratli, R. K. and Høeg, K. (2006): Brittle-ductile Transition, Shear Failure and Leakage in Shales and Mudrocks, Marine and Petroleum Geology, 23(2), 201-212.

17) Sridharan, A., Abraham, B. M. and Jose, B. T. (1991): Improved Technique for Estimation of Preconsolidation Pressure, Géotechnique, 41(41), 263-268.

18) The National Standards Compilation Group of People's Republic of China. (2001): Standard for Soil Test Method GB/T 50123-1999, Beijing, China Planning Press, 22-39 (in Chinese).

19) Wang, Z.L., Zhen, M.X. and Li, Y.C. (2005): Research on Mathematic Model Method for Calculating Preconsolidation Pressure and Its Application, Rock and Soil Mechanics, 26(10), 1587-1590 (in Chinese).

20) Yan, L.B., Liu, P., Peng, H., Kasanin Grubin, M. and Lin, K. (2018): Laboratory Study of The Effect of Temperature Difference on The Disintegration of Red Bed Soft Rock, Physical Geography, 40(2), 149-163.

21) Yuan, Y. S., Jin, Z. J., Zhou, Y., Liu, J.X., Li, S.J. and Liu, Q.Y. (2017): Burial Depth Interval of the Shale Brittle-ductile Transition Zone and Its Implications in Shale Gas Exploration and Production, Petroleum Science, 14, 637-647. 